\title{
A Critical Review on Obstetric Follow-up of Women Affected by Systemic Lupus Erythematosus
}

\section{Uma Revisão Crítica Sobre o Acompanhamento Obstétrico de Mulheres com Lúpus Eritematoso Sistêmico}

\author{
Danilo Eduardo Abib Pastore ${ }^{1}$ Maria Laura Costa ${ }^{1}$ Mary Angela Parpinelli ${ }^{1} \quad$ Fernanda Garanhani Surita ${ }^{1}$ \\ ${ }^{1}$ Department of Obstetrics and Gynecology, Universidade Estadual de \\ Campinas (Unicamp), Campinas, SP, Brazil \\ Rev Bras Ginecol Obstet 2018;40:209-224.

\begin{abstract}
Address for correspondence Fernanda Garanhani Surita, MD, PhD, Associate Professor, Department of Obstetrics and Gynecology, Universidade Estadual de Campinas - Unicamp, Rua Alexander Fleming, 101, Campinas, SP, 13083-881, Brazil (e-mail: surita@unicamp.br).
\end{abstract}

\begin{abstract}
Objective To review the existing recommendations on the prenatal care of women with systemic lupus erythematosus (SLE), based on currently available scientific evidence.

Methods An integrative review was performed by two independent researchers, based on the literature available in the MEDLINE (via PubMed), EMBASE and The Cochrane Library databases, using the medical subject headings (MeSH) terms "systemic lupus erythematosus" AND "high-risk pregnancy" OR "prenatal care." Studies published in English between 2007 and 2017 were included; experimental studies and case reports were excluded. In cases of disagreement regarding the inclusion of studies, a third senior researcher was consulted. Forty titles were initially identified; four duplicates were excluded. After reading the abstracts, 7 were further excluded and 29 were selected for a full-text evaluation.

Results Systemic lupus erythematosus flares, preeclampsia, gestation loss, preterm birth, fetal growth restriction and neonatal lupus syndromes (mainly congenital heartblock) were the major complications described. The multidisciplinary team should

\section{Keywords}

- systemic lupus erythematosus

- pregnancy

- prenatal care

- maternal outcomes

- fetal outcomes

Resumo adopt a specific monitoring, with particular therapeutic protocols. There are safe and effective drug options that should be prescribed for a good control of SLE activity. Conclusion Pregnant women with SLE present an increased risk for maternal complications, pregnancy loss and other adverse outcomes. The disease activity may worsen and, thereby, increase the risk of other maternal-fetal complications. Thus, maintaining an adequate control of disease activity and treating flares quickly should be a central goal during prenatal care.

Objetivo Revisar as recomendações existentes sobre o cuidado pré-natal às mulheres com lúpus eritematoso sistêmico (LES), com base em evidências científicas atualmente disponíveis.
\end{abstract}

received

November 1, 2017 accepted

December 20, 2017

published online

April 27, 2018
DOI https://doi.org/

10.1055/s-0038-1625951. ISSN 0100-7203.
Copyright $@ 2018$ by Thieme Revinter

Publicações Ltda, Rio de Janeiro, Brazil
License terms

(ㄷ) (i) $\ominus$ (5) 


\author{
Palavras-chave \\ - lúpus \\ eritematoso \\ sistêmico \\ - gravidez \\ - cuidado pré- \\ natal \\ - resultados \\ maternos \\ - resultados fetais
}

\begin{abstract}
Métodos Revisão integrativa realizada por dois pesquisadores independentes, com base na literatura disponível nos bancos de dados MEDLINE (via PubMed), EMBASE e The Cochrane Library, usando os cabeçalhos de assuntos médicos, ou termos MeSH, "systemic lupus erythematosus" E "high-risk pregnancy" OU "prenatal care." Estudos publicados em inglês entre 2007 e 2017 foram incluídos; estudos experimentais e relatos de caso foram excluídos. Em caso de desacordo, um terceiro pesquisador sênior foi consultado. Quarenta títulos foram inicialmente identificados; quatro duplicatas foram excluídas. Após leitura dos resumos, mais 7 artigos foram excluídos e 29 foram selecionados para uma avaliação de texto completo.

Resultados Surtos de LES, pré-eclâmpsia, perda de gestação, parto prematuro, restrição de crescimento fetal e síndromes de lúpus neonatal foram as principais complicações descritas. A equipe multidisciplinar deve adotar um monitoramento específico, com protocolos terapêuticos apropriados. Há drogas seguras e eficazes que devem ser prescritas para um bom controle do LES.

Conclusão Gestantes com LES apresentam risco aumentado de complicações maternas, perda de gravidez e outros desfechos adversos. A atividade da doença pode piorar e, assim, aumentar o risco de outras complicações. Assim, manter um controle adequado da atividade da doença e tratar rapidamente os surtos deve ser um objetivo central durante o pré-natal.
\end{abstract}

\section{Introduction}

\section{General Aspects}

Systemic lupus erythematosus (SLE) is an autoimmune and multisystemic disorder of the connective tissue that mainly affects women of childbearing age (about nine women for each man). Immune anomalies, particularly the production of a series of antinuclear antibodies, are another prominent feature of the disease. ${ }^{1}$

The SLE prevalence varies from 40 to 200 cases per 100,000 inhabitants, more common among Africans and Asians descendants. In Brazil, its prevalence is around 8.7 per 100,000 inhabitants. ${ }^{1,2}$

The broad spectrum of clinical presentations includes mucous-cutaneous, muscle-skeletal, hematological, cardiopulmonary, renal and central nervous system manifestations. The most severe forms of organ involvement are lupus nephritis and neuropsychiatric lupus, and these conditions may result in a significant reduction in life expectancy. ${ }^{1}$ Lupus nephritis is one of the leading causes of death along with infections. ${ }^{3}$

The most common general symptoms are weight loss, anemia, arthralgia and/or arthritis, being the involvement of the osteoarticular system the most frequent clinical manifestation. ${ }^{1}$ Antiphospholipid syndrome can occur in association with SLE, and it is characterized by arterial and venous thromboses, as well as recurrent morbidity in pregnancy. ${ }^{4}$

The American College of Rheumatology (ACR) proposed the criteria for the diagnosis of SLE $(-$ Table 1$) .^{5}$ To be classified as SLE, at least four criteria should occur in series or simultaneously. ${ }^{1,4,6}$

A consensus group of experts on SLE, the Systemic Lupus International Collaborating Clinics (SLICC), has proposed revised criteria for the diagnosis of SLE ( - Table 2 ). It requires either that a patient satisfies at least 4 out of 17 criteria, including at least one of the 11 clinical criteria and one of the 6 immunologic criteria, or that the patient has biopsy-proven nephritis compatible with SLE and positivity to antinuclear antibodies (ANA) or anti-double-stranded DNA (dsDNA) antibodies. $^{7}$

\section{Systemic Lupus Erythematosus and Pregnancy}

Considering the predilection of SLE in affecting women of childbearing age, pregnancy is of particular importance, with

Table 1 American College of Rheumatology (ACR) criteria for the classification of systemic lupus erythematosus

\begin{tabular}{|l|l|}
\hline 1. & Erythema malar. \\
\hline 2. & Discoid lupus. \\
\hline 3. & Photosensitivity. \\
\hline 4. & Oral ulcers. \\
\hline 5. & Arthritis. \\
\hline 6. & Serositis (pleuritis or pericarditis). \\
\hline 7. & $\begin{array}{l}\text { Nephropathy (persistent proteinuria greater } \\
\text { than 0.5 g/day and/or glomerular hematuria). }\end{array}$ \\
\hline 8. & Neurological disorders (convulsion or psychosis). \\
\hline 9. & $\begin{array}{l}\text { Hematologic disorders (hemolytic anemia, } \\
\text { leucopenia, thrombocytopenia). }\end{array}$ \\
\hline 10. & $\begin{array}{l}\text { Immune disorder (presence of LE cells, anti-DNA } \\
\text { or anti-Sm antibodies, false positive VDRL test, } \\
\text { anticardiolipin IgG or IgM antibodies, } \\
\text { lupus anticoagulant). }\end{array}$ \\
\hline 11. & Antinuclear antibody (ANA). \\
\hline
\end{tabular}

Abbreviations: IgG, immunoglobulin G; IgM, immunoglobulin M; LE, lupus erythematosus; Sm, smith; VDRL, venereal disease research laboratory. 
Table 2 Systemic lupus international collaborating clinics (SLICC) criteria for the classification of systemic lupus erythematosus (4 of 17 criteria, including at least one clinical criterion and one immunologic criterion; OR biopsy-proven lupus nephritis ${ }^{7}$

\begin{tabular}{|c|c|}
\hline Criterion & Clinical criteria \\
\hline Acute cutaneous lupus & $\begin{array}{l}\text { Lupus malar rash (do not count if malar discoid); bullous lupus; toxic epidermal necrolysis } \\
\text { variant of SLE; maculopapular lupus rash; photosensitive lupus rash (in the absence of } \\
\text { dermatomyositis); } \\
\text { OR subacute cutaneous lupus (nonindurated psoriasiform and/or annular polycyclic lesions } \\
\text { that resolve without scarring, although occasionally with postinflammatory dyspigmentation } \\
\text { or telangiectasias) }\end{array}$ \\
\hline Chronic cutaneous lupus & $\begin{array}{l}\text { Classic discoid rash; localized (above the neck); generalized (above and below the neck); } \\
\text { hypertrophic (verrucous) lupus; lupus panniculitis (profundus); mucosal lupus; lupus } \\
\text { erythematosus tumidus; chilblains lupus; OR discoid lupus/lichen planus overlap }\end{array}$ \\
\hline Nonscarring alopecia & $\begin{array}{l}\text { Diffuse thinning or hair fragility with visible broken hairs (in the absence of other causes, such } \\
\text { as alopecia areata, drugs, iron deficiency, and androgenic alopecia) }\end{array}$ \\
\hline Oral or nasal ulcers & $\begin{array}{l}\text { Palate, buccal, tongue, OR nasal ulcers (in the absence of other causes, such as vasculitis, } \\
\text { Behçet disease, infection [herpesvirus], inflammatory bowel disease, reactive arthritis, and } \\
\text { acidic foods) }\end{array}$ \\
\hline Joint disease & $\begin{array}{l}\text { Synovitis involving two or more joints, characterized by swelling or effusion OR tenderness in } \\
\text { two or more joints and at least } 30 \text { minutes of morning stiffness }\end{array}$ \\
\hline Serositis & $\begin{array}{l}\text { Typical pleurisy for more than one day, pleural effusions, or pleural rub, OR } \\
\text { typical pericardial pain (pain with recumbency improved by sitting forward) for more than one } \\
\text { day, pericardial effusion, pericardial rub, or pericarditis by electrocardiography in the absence } \\
\text { of other causes, such as infection, uremia, and Dressler's syndrome }\end{array}$ \\
\hline Renal & $\begin{array}{l}\text { Urine protein-to-creatinine ratio (or 24-hour urine protein) representing } 500 \text { mg protein/ } \\
24 \text { hours, OR red blood cell casts }\end{array}$ \\
\hline Neurologic & $\begin{array}{l}\text { Seizures; psychosis; mononeuritis multiplex (in the absence of other known causes, such as } \\
\text { primary vasculitis); myelitis; peripheral or cranial neuropathy (in the absence of other known } \\
\text { causes, such as primary vasculitis, infection, and diabetes mellitus); OR acute confusional state } \\
\text { (in the absence of other causes, including toxic/metabolic, uremia, drugs) }\end{array}$ \\
\hline Hemolytic anemia & Hemolytic anemia \\
\hline Leukopenia or lymphopenia & $\begin{array}{l}\text { Leukopenia ( }<4,000 / \mathrm{mm}^{3} \text { at least once) (in the absence of other known causes, such as Felty } \\
\text { syndrome, drugs, and portal hypertension), OR lymphopenia }\left(<1,000 / \mathrm{mm}^{3} \text { at least once) }\right. \\
\text { (in the absence of other known causes, such as glucocorticoids, drugs, and infection) }\end{array}$ \\
\hline Thrombocytopenia & $\begin{array}{l}\text { Thrombocytopenia }\left(<100,000 / \mathrm{mm}^{3}\right) \text { at least once in the absence of other known causes, such } \\
\text { as drugs, portal hypertension, and thrombotic thrombocytopenic purpura }\end{array}$ \\
\hline \multicolumn{2}{|l|}{ Immunologic criteria } \\
\hline ANA & ANA level above laboratory reference range \\
\hline Anti-dsDNA & $\begin{array}{l}\text { Anti-dsDNA antibody level above laboratory reference range (or }>2 \text {-fold the reference range } \\
\text { if tested by ELISA) }\end{array}$ \\
\hline Anti-Sm & Presence of antibody to Sm nuclear antigen \\
\hline Antiphospholipid & $\begin{array}{l}\text { Antiphospholipid antibody positivity as determined by any of the following: Positive test result } \\
\text { for lupus anticoagulant; false-positive test result for rapid plasma reagin; medium- or high-titer } \\
\text { anticardiolipin antibody level (IgA, IgG, or lgM); or positive test result for anti- } \beta \text { 2-glycoprotein } \\
\text { I ( } \operatorname{lgA}, \lg G \text {, or } \lg M)\end{array}$ \\
\hline Low complement & Low C3; low C4; OR low CH50 \\
\hline Direct Coombs test & Direct Coombs test in the absence of hemolytic anemia \\
\hline
\end{tabular}

Abbreviations: ANA, antinuclear antibodies; ELISA, enzyme-linked immunosorbent assay; SLE, systemic lupus erythematosus.

relevant impact in maternal and perinatal health. ${ }^{8}$ The incidence of SLE among pregnant women ranges from $1: 660$ to $1: 2.952$; therefore, an understanding on how to manage these patients is essential. ${ }^{9}$

Although advances in the treatment of obstetric complications and improvements in neonatal care have enabled lupus women to have pregnancies with better outcomes, SLE persists associated with significant fetal and maternal morbidity. ${ }^{8}$
Conditions with elevated levels of estrogen, such as pregnancy, have the potential to exacerbate SLE. The incidence of disease outbreaks during pregnancy varies between 15 and 63\%. ${ }^{10}$

The impact of pregnancy in the course of lupus remains controversial, especially in relation to the incidence of flares. In contrast, the impact of lupus on gestation is more clearly understood. Women with lupus are no less fertile; outcomes are characterized by higher rates of fetal loss, preterm birth, 
and fetal growth restriction (FGR), higher incidence of hypertensive disorders and maternal intensive care admission. Multiple factors have been identified in association with adverse outcomes, such as lupus activity during pregnancy, previous nephropathy, maternal hypertension, and positivity for anti-phospholipid antibodies. ${ }^{8}$

Thus, adopting a specific protocol of care for pregnant women with lupus should contribute to reduce the frequency of maternal and fetal adverse outcomes, directly or indirectly related to SLE, improving care standards and ensuring successful pregnancies. This review aims to disclose the existing recommendations on prenatal care among health professionals attending pregnant women affected by SLE, based on currently available scientific evidence.

\section{Methods}

Integrative reviews were conducted to develop an evidencebased context in relation to different perspectives of clinical science studies. The following medical subject headings (MeSH) terms were used for research: "systemic lupus erythematosus" AND "high-risk pregnancy” OR "prenatal care.” Different scientific databases were analyzed: MEDLINE(via PubMed), EMBASE and The Cochrane Library.
The inclusion criteria comprised studies published in English language, between 2007 and 2017 Experimental articles and case reports were excluded. Two independent researchers performed the search strategy in the scientific databases and, if there were disagreements regarding the final inclusion, a third senior researcher was consulted.

We found a total of 40 articles; 29 were accessed in full-text and selected for a qualitative synthesis (-Fig. 1). - Table 3 summarizes their methodologies, results and conclusions.

\section{Results}

\section{Preconception Orientation}

Adequate counselling, planning and care before, during and after the pregnancy must be the goal of health professionals who look after women with SLE. Luckily, multidisciplinary units are increasingly integrating different medical specialists (including obstetricians, immunologists, rheumatologists, hematologists and nephrologists), which may allow for a more coordinated management of pregnancy along with disease activity. ${ }^{35}$

The care of pregnant women with SLE must focus on three mainstays: a coordinated medical-obstetrical care, a welldefined management protocol and a well-structured

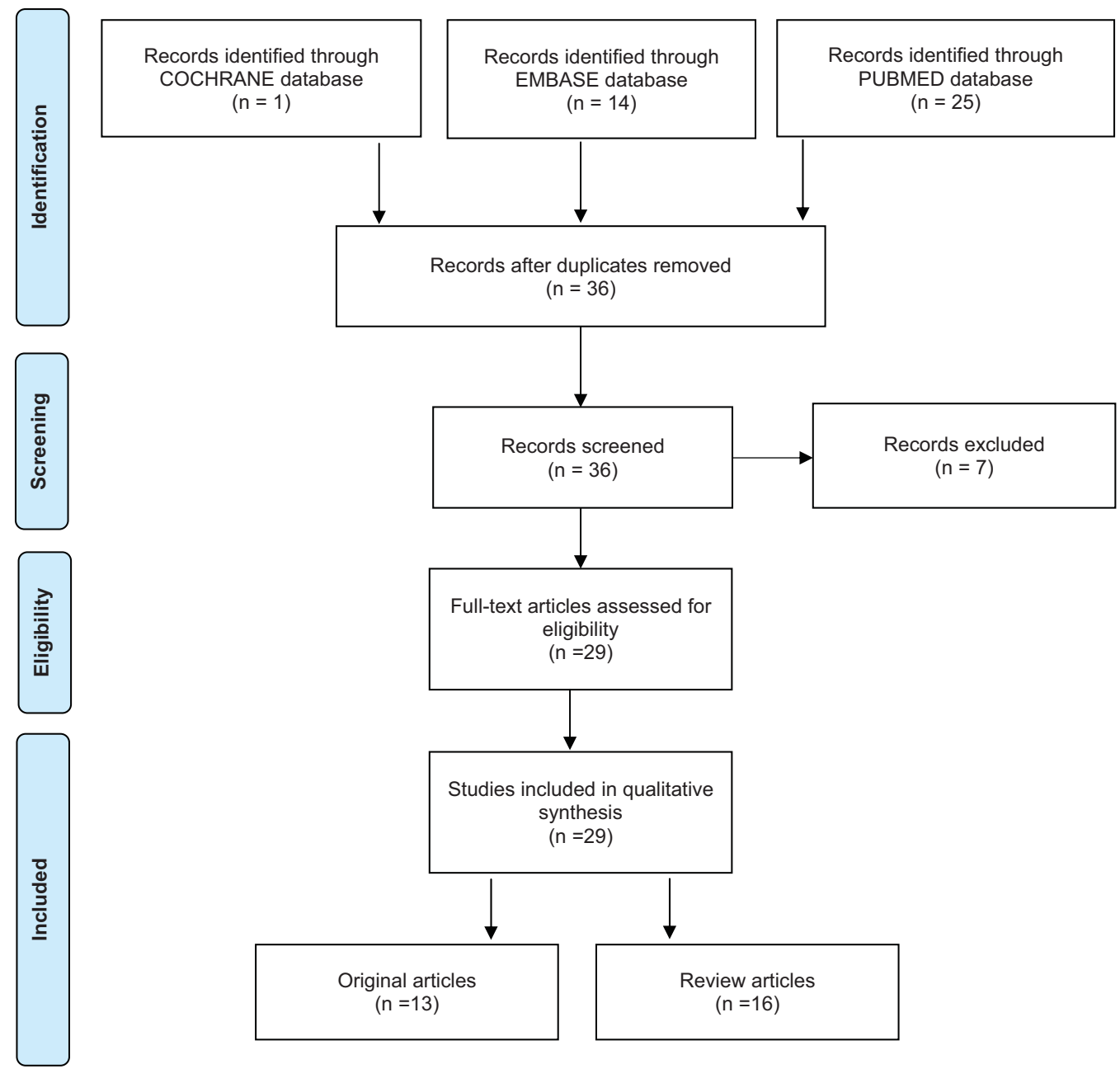

Fig. 1 PRISMA 2009 flow diagram for article's inclusion on obstetric follow-up of women affected by systemic lupus erythematosus. 


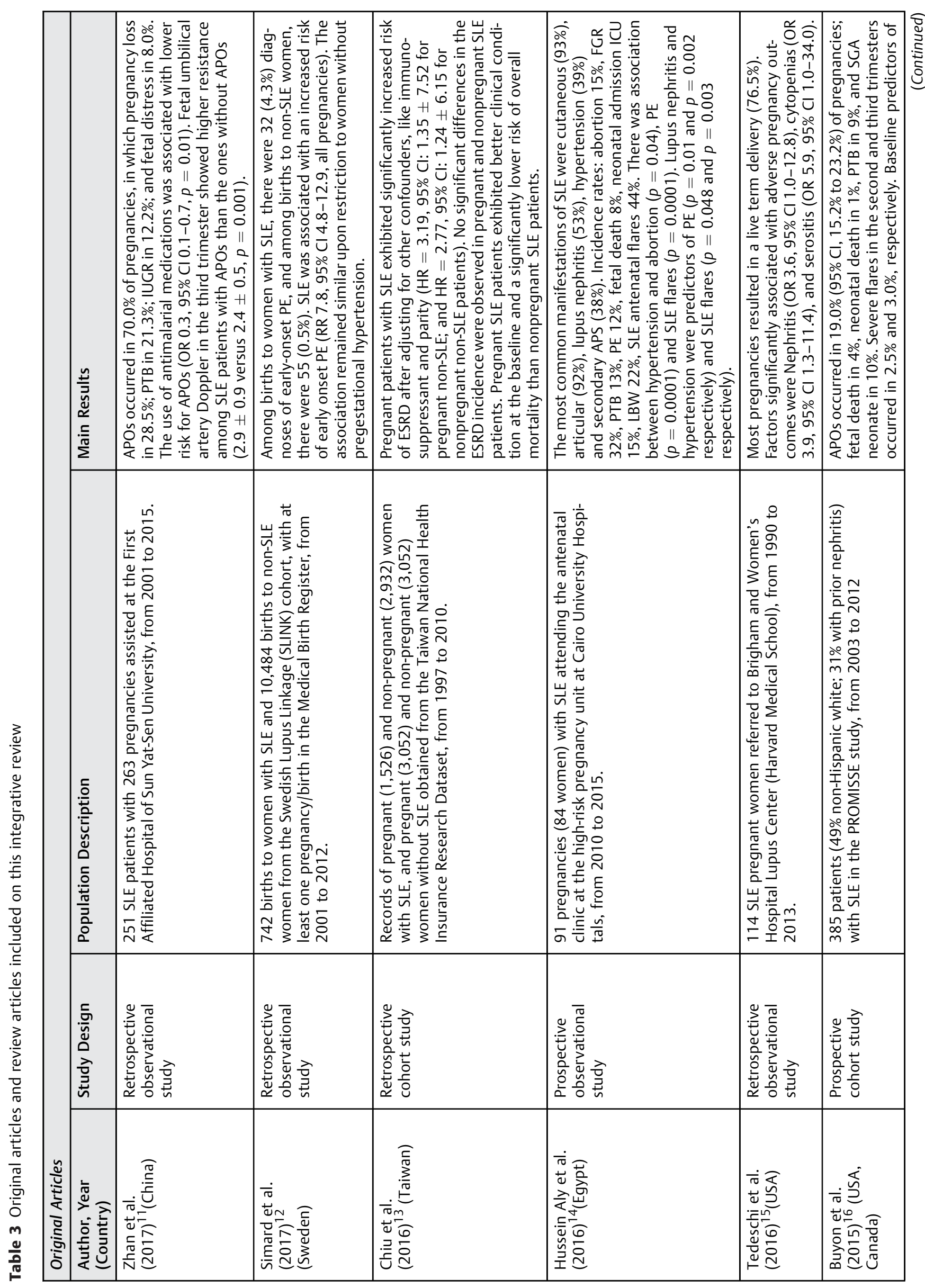




\begin{tabular}{|c|c|c|c|c|c|}
\hline & 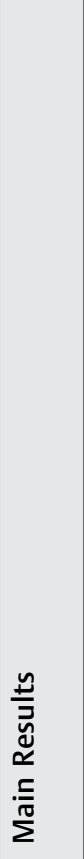 & 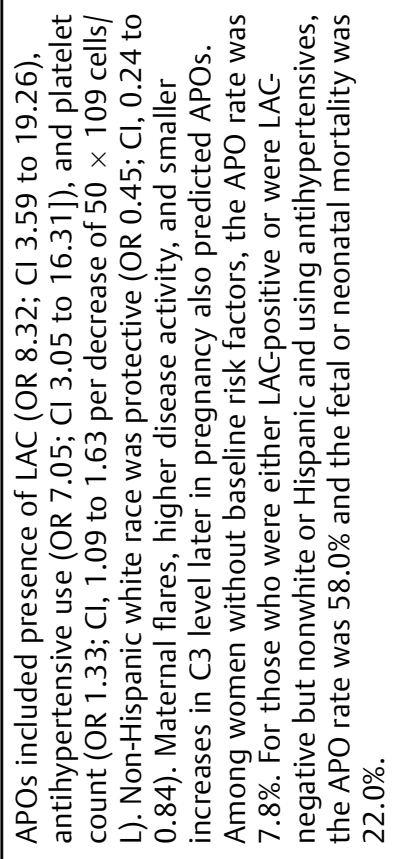 & 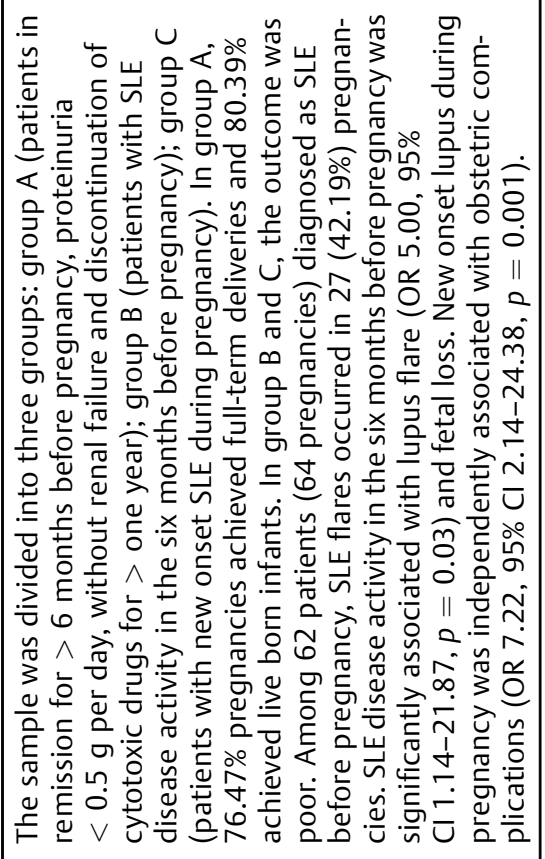 & 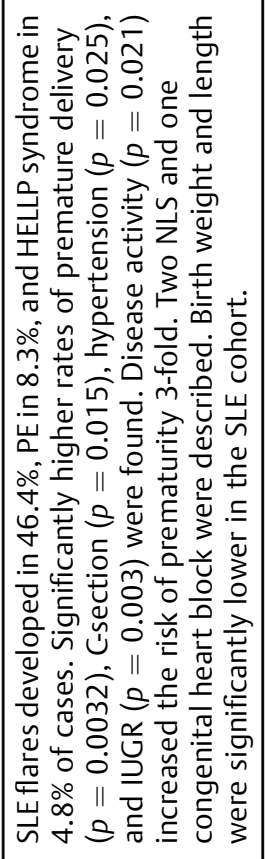 & 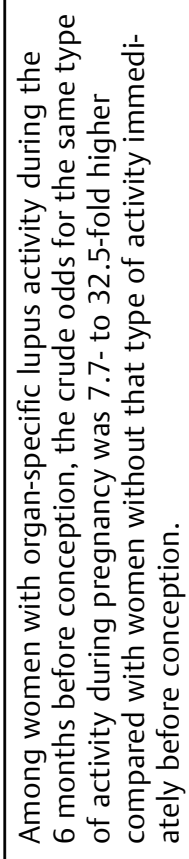 \\
\hline & 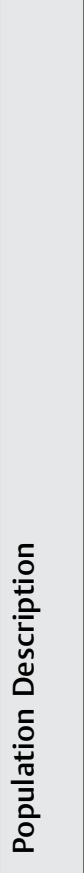 & & 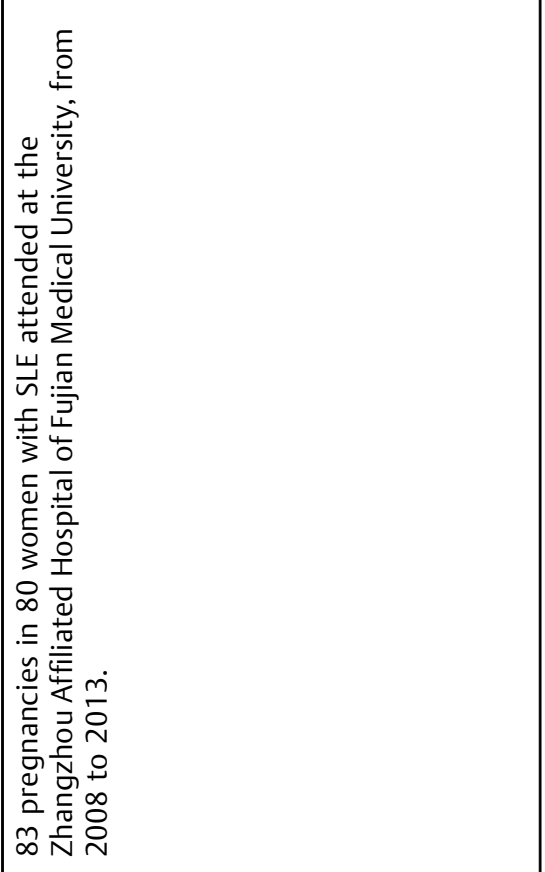 & 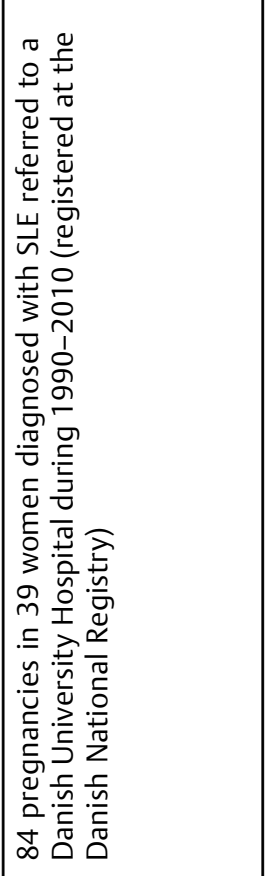 & 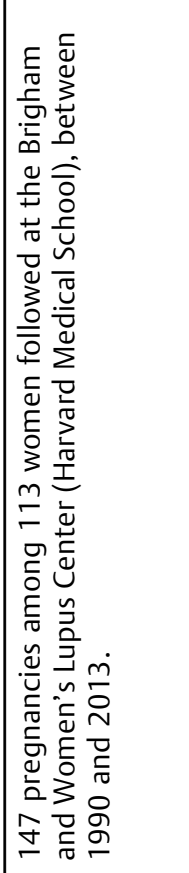 \\
\hline & 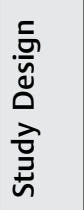 & & 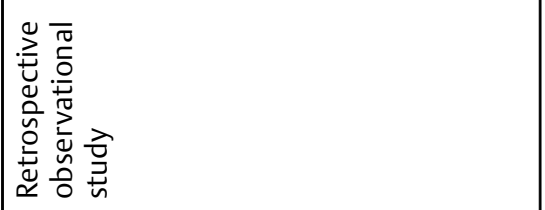 & 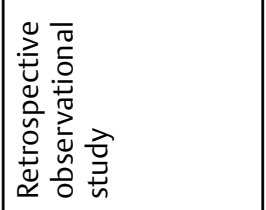 & 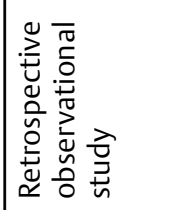 \\
\hline 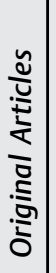 & 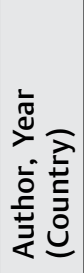 & & 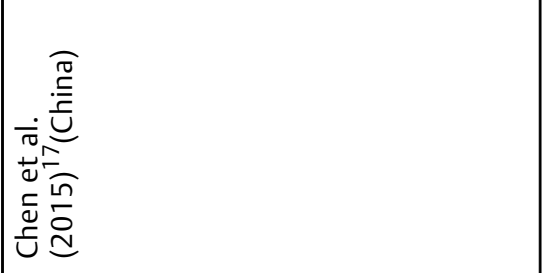 & 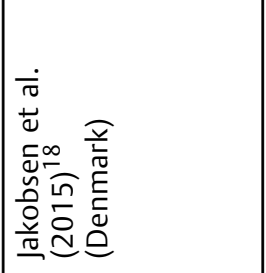 & 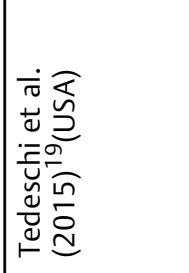 \\
\hline
\end{tabular}




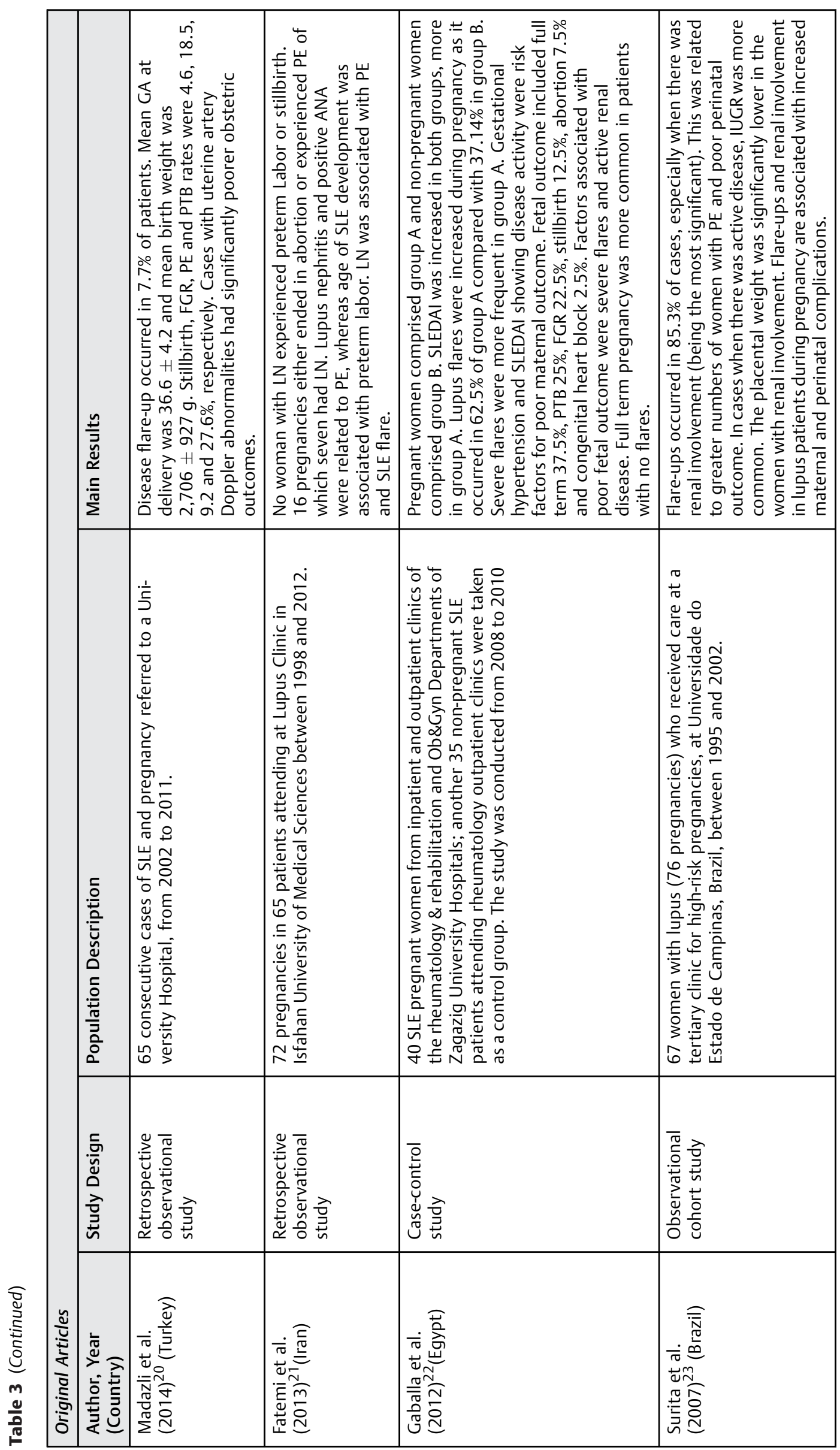




\begin{tabular}{|c|c|c|c|c|c|c|c|}
\hline & 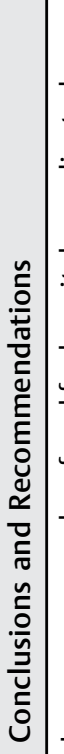 & 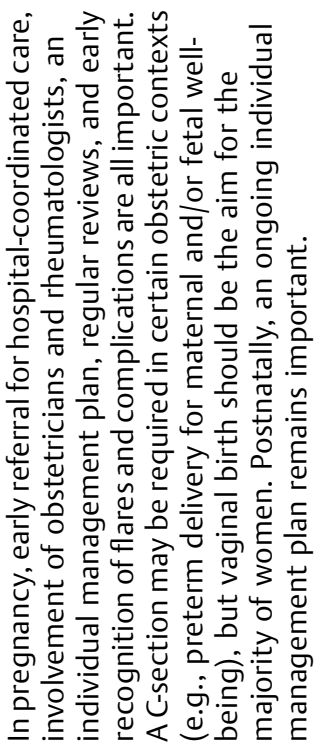 & 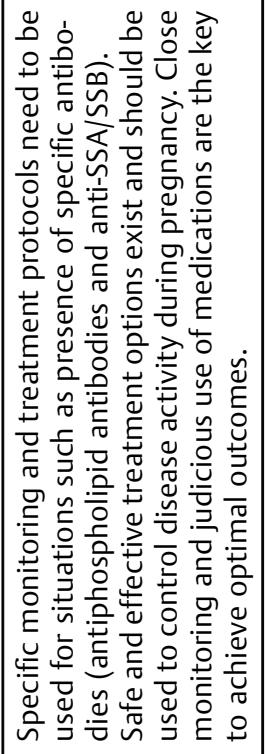 & 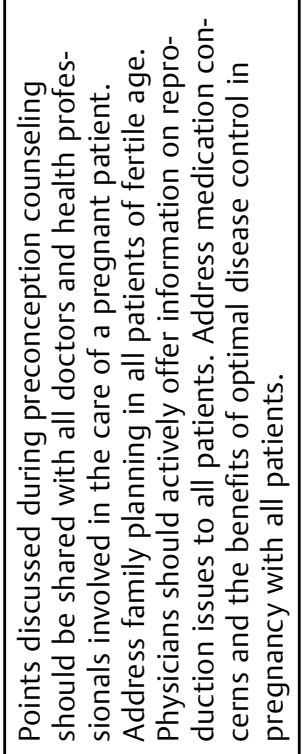 & 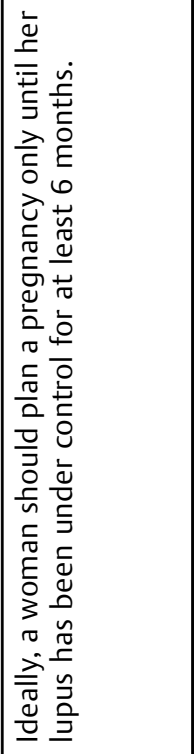 & 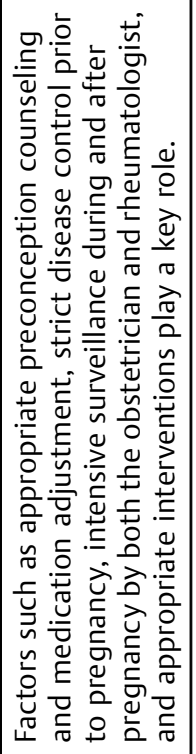 & 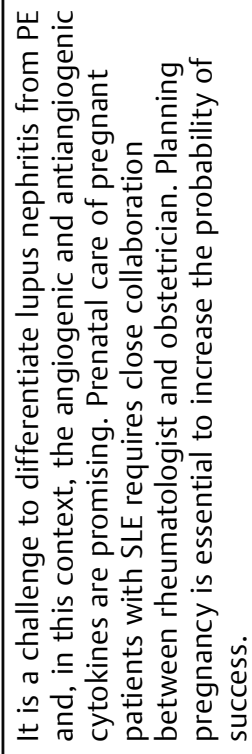 \\
\hline & 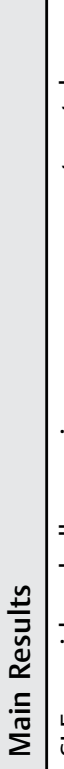 & 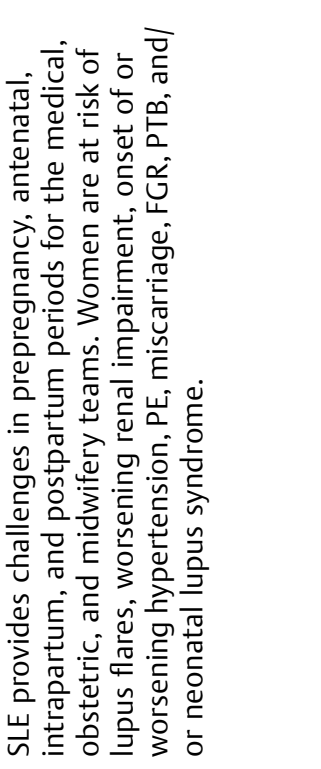 & 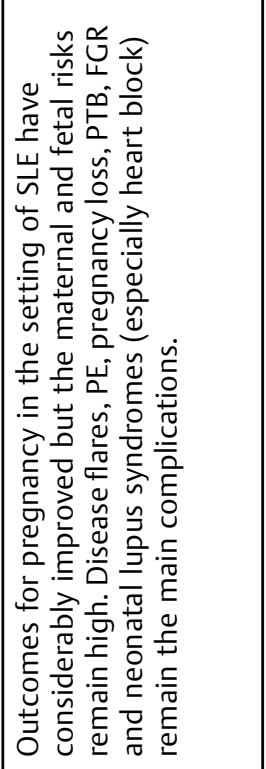 & 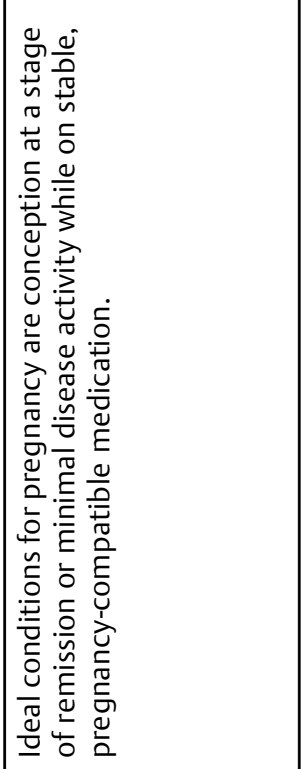 & 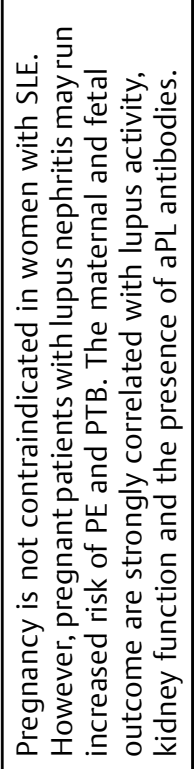 & 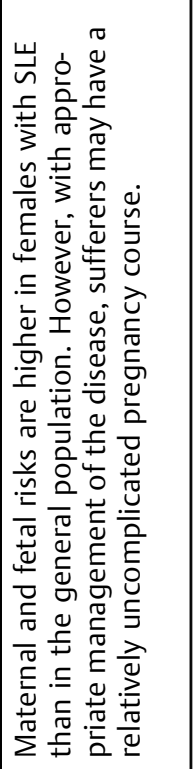 & 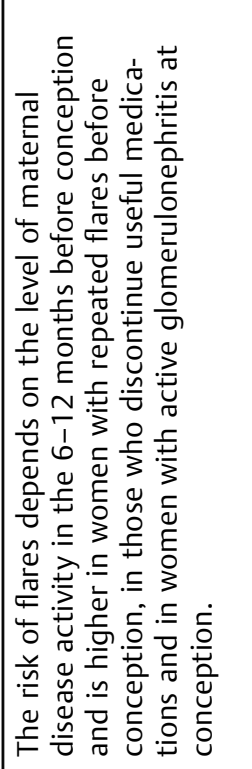 \\
\hline & 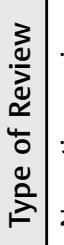 & 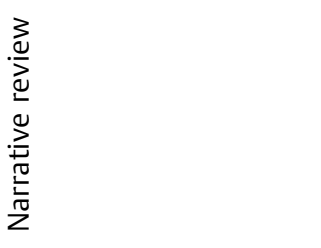 & 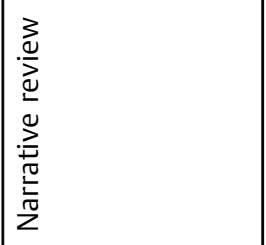 & 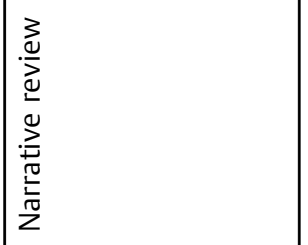 & 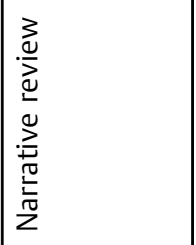 & 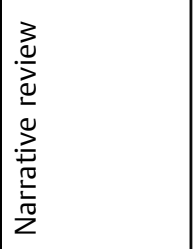 & 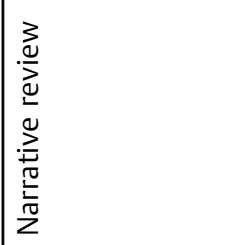 \\
\hline & 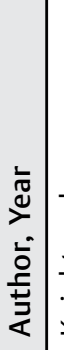 & 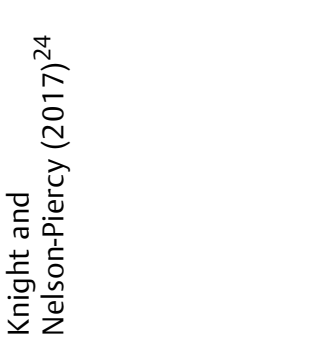 & 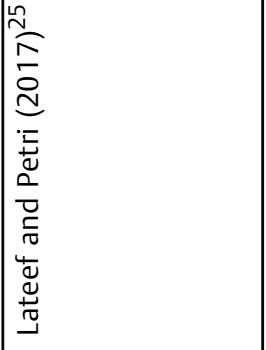 & 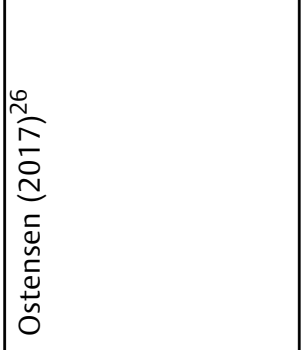 & 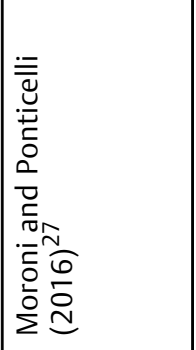 & 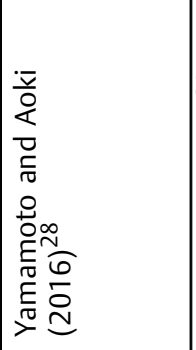 & 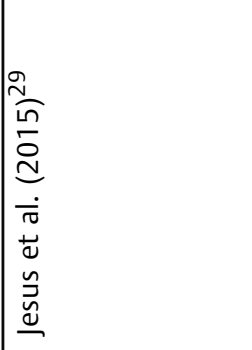 \\
\hline
\end{tabular}




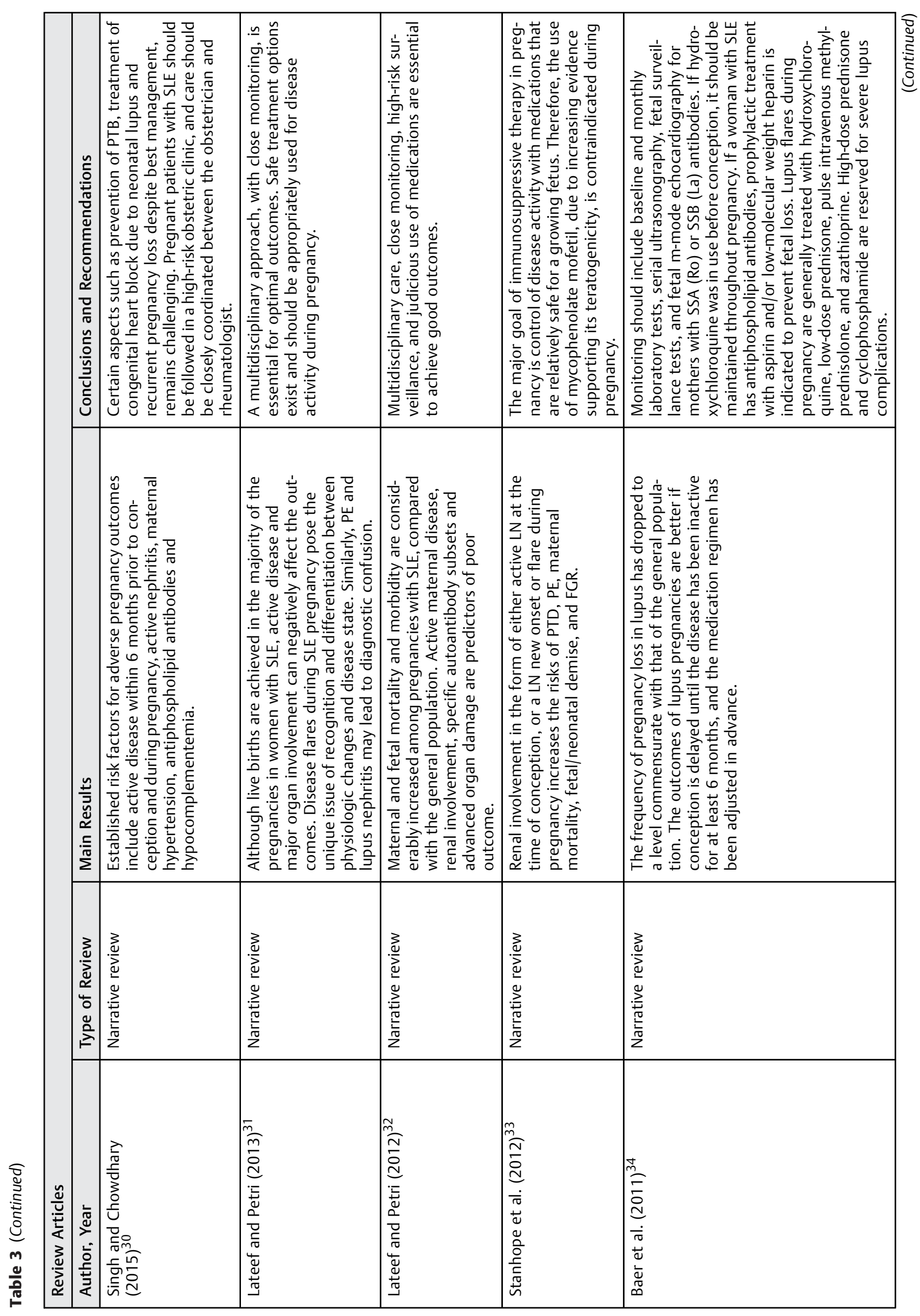




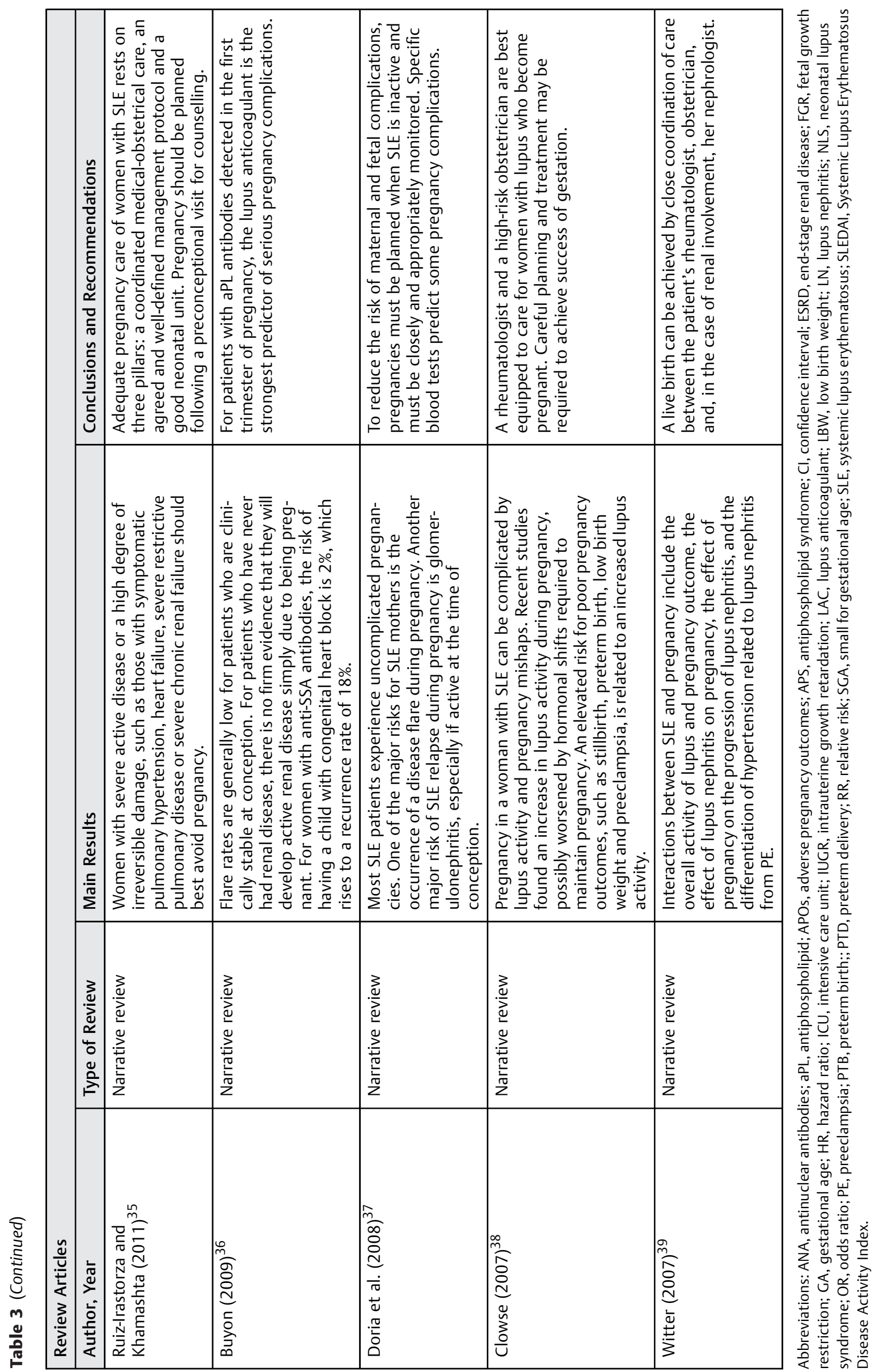


neonatal unit. Preconception counselling is vital to assess the chance of both potential fetal and maternal complications; that way, consistent information regarding specific risk for complications and the expected management plan should be provided (- Table 3$)^{35}$

Pregnancy planning is a key-point for women with SLE. Postponing conception until the disease is considered inactive for at least six months significantly improves the outcomes of these pregnancies. ${ }^{26,31,34,35}$ Women who present some form of irreparable organ injury are more likely to undergo complications and even additional damage during and after pregnancy. Some conditions should advise to delay pregnancy, such as severe disease flare within the previous six months, recent stroke and active lupus nephritis. ${ }^{32}$ In some situations, pregnancy may be contraindicated (- Table 4). ${ }^{26,34,35}$

At the preconception visit, obtaining a complete set of autoantibody profile is recommended, including antiphospholipid (aPL) antibodies (anticardiolipin and lupus anticoagulant), complement serum levels, anti-SSA and anti-SSB antibodies. Evaluating the pregnancy risk and assessing the SLE activity and the organ function is important to maintain disease control only in safe medications. ${ }^{32}$

A higher risk of complications is found among women with severe impairment of organ function, with or without preexisting severe organ damage. ${ }^{24}$ Besides, the diagnosis of SLE during pregnancy is also related to the occurrence of complications, significantly affecting maternal and fetal outcomes. ${ }^{30}$

\section{Prenatal Follow-up}

\section{General Findings}

The prenatal care of a woman with SLE requires close collaboration between the obstetrician and the clinicians (rheumatologist, nephrologist or hematologist), and management in a high-risk referral center. An evaluation by the clinician should occur every 4-6 weeks, whereas the obstet- ric visit should be every 4 weeks until 20 weeks of gestation; then, every 2 weeks until 28 weeks, and then, weekly until the expected delivery date. ${ }^{34}$

At every prenatal visit, blood pressure, weight gain, uterine size, fetal heart rate and urinalysis (through a quick outpatient analysis with the dipstick testing) should be assessed, as well as inquiring about symptoms related to lupus flares. ${ }^{34}$

The differential diagnosis of complications that may arise during pregnancy is not easy. Signs and symptoms of lupus flares often mimic the ones of normal pregnancy. Those flares are less frequent in the third trimester, although they may occur at any time during pregnancy or in the immediate postpartum period. ${ }^{34}$

\section{Laboratory Evaluation during Prenatal Care}

In addition to routine pregnancy booking, blood tests (which include a full blood count), baseline tests of renal and hepatic function and baseline urinary protein quantified by a 24hour collection should be obtained. ${ }^{24}$ Complement studies should comprise further tests ( $\mathrm{C} 3, \mathrm{C} 4, \mathrm{CH} 5 \mathrm{O})$, anticardiolipin antibodies, anti-dsDNA, lupus anticoagulant and anti-SSA and SSB.

\section{Disease Activity during Prenatal Care (Flares)}

Changes in hormonal levels through pregnancy prompt to a shift from Th1 to Th2 lymphocyte dominance; consequently, autoimmune disorders involving Th2-response, such as SLE, are expected to flare. ${ }^{24}$

It is generally agreed that pregnancy may lead to higher rates of disease flares, with rates from 25 to $65 \%$ being reported. ${ }^{18,31,37}$ Different organ systems may have variable response to pregnancy; musculoskeletal flares are less common, whereas renal and hematological flares are more common. ${ }^{31}$ The risk of flare seems to be related to the occurrence of disease activity 6-12 months before conception. ${ }^{15,19,22,24,30}$

Table 4 Preconception visit checklist and contraindications to pregnancy in women with SLE ${ }^{35}$

\begin{tabular}{|l|l|}
\hline Preconception visit checklist & Contraindications to pregnancy \\
\hline Age? & Severe lupus flare within the previous 6 months \\
\hline Any previous pregnancy? & Severe restrictive lung disease (FVC < $1 \mathrm{~L})$ \\
\hline Previous pregnancy complications? & Heart failure \\
\hline Presence of severe irreversible damage? & Chronic renal failure (Cr $>28 \mathrm{mg} / \mathrm{dL})$ \\
\hline Recent or current lupus activity? & Stroke within the previous 6 months \\
\hline Presence of antiphospholipid antibodies/syndrome? & $\begin{array}{l}\text { Previous severe preeclampsia or HELLP syndrome } \\
\text { despite therapy with aspirin and heparin }\end{array}$ \\
\cline { 1 - 2 } $\begin{array}{l}\text { Other chronic medical conditions? } \\
\text { (Hypertension, diabetes, etc.) }\end{array}$ & $\begin{array}{l}\text { Severe pulmonary hypertension } \\
\text { (estimated systolic PAP }>50 \text { mm Hg or symptomatic) }\end{array}$ \\
\cline { 1 - 2 } $\begin{array}{l}\text { Current treatment: any “forbidden” drugs? } \\
\text { (including cyclophosphamide, methotrexate, mycophenolate, } \\
\text { angiotensin converting enzyme inhibitors, angiotensin II } \\
\text { receptor blockers, diuretics and statins) }\end{array}$ & \\
\cline { 1 - 2 } Positivity of anti-SSA /anti-SSB? & \\
\cline { 1 - 2 } Smoking? & \\
\hline
\end{tabular}

Abbreviations: FVC, forced vital capacity; PAP, pulmonary arterial pressure. 
A higher risk of flare during pregnancy is noticed when lupus nephritis occurs at conception, even in women in remission. ${ }^{13,21,24,30}$ One study showed a $30 \%$ flare rate during pregnancy or postpartum among 113 pregnancies in women with preexisting lupus nephritis evaluated; other studies suggest a likelihood of up to $60 \%{ }^{24}$ Besides, different reports in the literature indicate lupus nephritis as a predictive of poor prognosis for pregnancy. ${ }^{23}$

It may be difficult to distinguish pregnancy-related signs and symptoms from those of SLE. Therefore, an appropriate assessment by experienced physicians is important. $24,37,38$ Ambiguous manifestations include fatigue, headaches, arthralgia, edema, hair loss, dyspnea, malar and palmar erythema, anemia and thrombocytopenia. Hence, baseline blood counts and urinalysis with measurement of proteinuria assessed early in gestation are helpful to monitor disease status and identify flares. ${ }^{24}$

During pregnancy, liver production of serum C3 and C4 increases, so their levels may persist within the range of normality in cases of active SLE. Relative variations are more important, rather than absolute levels, with a drop of $\geq 25 \%$ in serum complement levels suggesting lupus flare. ${ }^{24}$

Pregnancy-specific disease activity scales (such as systemic lupus erythematosus pregnancy disease activity index [SLEPDAI] and lupus activity index in pregnancy [LAI-P]) have been developed, but mostly remain as research tools. In practice, the clinical judgment of an experienced clinician is still considered the gold standard. ${ }^{25,31,32}$ The SLEPDAI scale is a similar instrument to the systemic lupus erythematosus disease activity index (SLEDAI) for assessment of lupus activity, assigning different scores for the various clinical and laboratory manifestations of lupus activity, however taking into account the physiological changes of gestation and the main pathologies of the pregnancy-puerperal cycle that can mimic SLE in activity. Its score ranges from zero to 105 and stratifies the disease activity: absent (up to 4 points), mild to moderate (5-12 points) and severe (up to 12 points) (- Table 5 ). ${ }^{36}$

A recent meta-analysis reported rates ranging from 1.5 to $83 \%$ for a lupus nephrites flare during pregnancy, ${ }^{33}$ corroborating with data from previous studies. ${ }^{38}$ Thus, it is strongly recommended a close monitoring, with monthly assessments of disease activity (with special attention to renal function). Besides, the risk of hypertensive disorders of pregnancy increases in the setting of active lupus nephritis. ${ }^{14,33}$

The frequency of preeclampsia varies from 7.5 to $22.5 \%$ for all women with SLE. ${ }^{12,15,18,20,39}$ Lupus renal involvement is often associated with hypertension, and the preeclampsia diagnosis is difficult, since it may be superimposed on chronic hypertension. ${ }^{39}$

Likewise, in cases of SLE women with glomerular lesions, increased proteinuria may be observed, due to the enlarged glomerular filtration rate during pregnancy, with this fact not being related to preeclampsia. Thus, the diagnosis of preeclampsia can get more difficult because of increasing blood pressure and proteinuria at term. ${ }^{38,39}$

The differential diagnosis of preeclampsia in lupus patients may be facilitated by changes in the measures of C3, C4 and CH50, since a reduction in those levels is expected during lupus activity. ${ }^{39}$ Other laboratory test findings may be helpful to successfully perform a differential diagnosis: abnormal urinary sedimentation with the presence of erythrocyte dysmorphism or cell casts and increased anti-DNA antibody titers (all found in lupus nephritis). ${ }^{23}$

New onset SLE during pregnancy can be considered as SLE activity and might be associated with worse outcome. Differentiating the diagnosis of preeclampsia from new onset SLE during pregnancy is a challenge and frequently delays the diagnosis of SLE. However, a Chinese study indicated that new onset SLE during the third trimester of pregnancy might have a better outcome. ${ }^{17}$

Among patients with stable condition at the time of conception, it is expected that disease activity will not worsen, and even if so, the flare is usually mild and occasionally involves some kind of treatment modification. ${ }^{28}$

\section{Evaluation of Fetal Growth and Vitality}

Fetal complications are frequently observed in patients with SLE. Overall, miscarriages and stillbirth may occur in $\sim 20 \%$ of pregnancies in SLE patients. ${ }^{11,15,26,30}$ Patients with a history of nephritis, in special, have an increased risk for such adverse outcomes. $^{14,16}$

The rate of FGR is estimated to be near of $30 \%$, observed even in mild disease, with an increased risk if there is renal involvement. Small-for-gestational-age is a more common outcome in those born prematurely, but can occur at all gestational ages. ${ }^{20,22,37,39}$ Several studies concluded that the small-for-gestational-age rate outcome among SLE women tends to be higher, condition strongly associated to the presence of disease flare-ups during pregnancy. ${ }^{23}$

Serial obstetric sonography is the most important method to guide surveillance for fetal growth. Crown-rump length measurement in the first trimester presents as the most precise measurement. At 16 to 22 weeks of gestation, an anatomic survey considering diagnosis of fetal anomalies should be followed, also serving to allow the first monitoring of growth. At each 4-week periods, new scans should take place, with measurement of amniotic fluid volume. If preeclampsia or FGR are diagnosed, the interval can be reduced to 3 weeks. ${ }^{39}$

Fetal vitality surveillance is an important part of the prenatal care of SLE patients. This should include the nonstress test (NST), the biophysical profile (BPP), and fetal umbilical artery Doppler velocimetry, starting at 26 to 28 weeks and continuing weekly until birth. ${ }^{39}$

In patients with SLE, alterations of umbilical artery Doppler velocimetry should be managed similarly to those without the condition. Normal evaluation of these tests has a high negative predictive value for fetal death. ${ }^{29}$ Association between abnormal uterine artery Doppler and later fetal loss, preeclampsia, FGR and preterm labor were also described. ${ }^{29}$

Because of the risk of fetal congenital heart block, for women with anti-SSA/SSB antibodies, a fetal echocardiography should be performed at 18-20 weeks and 26-28 weeks to exclude fetal congenital heart block. An urgent referral to a tertiary care center should be prompted in case of any fetal heart rate abnormality, mostly a slow heart rate. ${ }^{24}$ 
Table 5 Systemic lupus erythematosus pregnancy disease activity index (SLEPDAI) instrument to stratify SLE activity during pregnancy $^{36}$

\begin{tabular}{|c|c|c|c|}
\hline Score & Descriptor & $\begin{array}{l}\text { Modified for } \\
\text { pregnancy }\end{array}$ & Considerations \\
\hline 8 & Seizure & Yes & (r/o eclampsia) \\
\hline 8 & Psychosis & No & \\
\hline 8 & Organic brain syndrome & No & \\
\hline 8 & Visual disturbance & No & $\begin{array}{l}\text { (hypertension is already considered an exclusion in } \\
\text { SELENA-SLEDAI and SLEDAI) }\end{array}$ \\
\hline 8 & Cranial nerve disorder & Yes & (r/o Bell palsy) \\
\hline 8 & Lupus headache & Yes & (r/o Bell palsy) \\
\hline 8 & CVA & Yes & (r/o eclampsia) \\
\hline 8 & Vasculitis & Yes & (consider palmar erythema) \\
\hline 4 & Arthritis & Yes & (consider bland knee effusions) \\
\hline 4 & Myositis & No & \\
\hline 4 & Urinary casts & No & \\
\hline 4 & Hematuria & Yes & ( $r / 0$ cystitis and vaginal RBC reflective of placental problems) \\
\hline 4 & Proteinuria & Yes & (r/o eclampsia) \\
\hline 4 & Pyuria & Yes & (r/o infection) \\
\hline 2 & Rash & Yes & (consider chloasma) \\
\hline 2 & Alopecia & Yes & (consider normal postpartum alopecia) \\
\hline 2 & Mucosal Ulcers & No & \\
\hline 2 & Pleurisy & Yes & $\begin{array}{l}\text { (hyperventilation may be secondary to progesterone, } \\
\text { dyspnea secondary to enlarging uterus) }\end{array}$ \\
\hline 2 & Pericarditis & No & \\
\hline 2 & Low complement & Yes & (complements normally rise during pregnancy) \\
\hline 2 & Increased DNA binding & No & \\
\hline 1 & Thrombocytopenia & Yes & $\begin{array}{l}\text { (r/o preeclampsia, HELLP syndrome, incidental } \\
\text { thrombocytopenia of pregnancy) }\end{array}$ \\
\hline 1 & Leukopenia & Yes & (consider normal rise of leukocyte count during pregnancy) \\
\hline 1 & Fever & No & \\
\hline
\end{tabular}

Abbreviation: CVA, cerebrovascular accident; RBC, red blood cell; r/o: rule out, SELENA-SLEDAI, safety of estrogens in lupus erythematosus national assessment- systemic lupus erythematosus pregnancy activity index; SLEDAI, systemic lupus erythematosus pregnancy activity index.

\section{Recommended SLE Treatment during Pregnancy}

Considering the harmful effects of active disease on both mother and fetus, an appropriate reflection between the risks and benefits of this treatment must take place. ${ }^{26,30}$

In practice, it is frequent that SLE women to discontinue their medication before conception, due to fear of fetotoxicity, without proper doctor counseling. However, discontinuation of the medication may lead to active SLE and unfavorable pregnancy outcomes. ${ }^{28}$

Usually, the immunosuppressive treatment in pregnant women with quiescent lupus should not be changed. The most frequently used agents in lupus patients are glucocorticoids and hydroxychloroquine, which should be maintained. ${ }^{27}$

Prednisone at a dosage of $5-10 \mathrm{mg}$ per day is usually considered safe. ${ }^{27}$ Lupus flares that fit into mild activity can be treated with low-dose prednisone (less than $20 \mathrm{mg} / \mathrm{d}$ ). Higher doses of corticosteroids, including pulse dose steroids, are options to treat moderate to severe lupus activity. ${ }^{37,38}$
Hydroxychloroquine is not a teratogenic drug. Its use is recommended to prevent disease activity and reduce the risk of cardiac-neonatal lupus in patients who are carriers of antiSSA/-antibody. ${ }^{11,27,28}$ In addition, it improves the prognosis of SLE nephritis and prevents death. ${ }^{38}$

Azathioprine is considered safe, especially if compared with other immunosuppressive drugs. Many studies sustain a transition to this option if the patient wishes to conceive. However, some other reports recently pointed out concerns about late developmental delays in children who were exposed to azathioprine during pregnancy, ${ }^{28,38}$ as well as neonatal leucopenia and/or thrombocytopenia. ${ }^{27}$

Regarding cyclosporine and tacrolimus, the FDA classifies as category C; however, some meta-analysis studies did not find significant differences related to birth defects when pregnant women were exposed to them. ${ }^{27,37}$

Cyclophosphamide should not be prescribed during the first trimester, because of its association to chromosomal 
impairment. During the second or third trimester, it should be reserved only to severe flares unamenable with methylprednisolone pulses or other drugs. The use of cyclophosphamide during the second and third trimesters does not seem to increase the risk for congenital abnormalities. Nevertheless, miscarriages and preterm birth may be more frequent. ${ }^{27,37}$

Leflunomide is associated to teratogenic and fetotoxic effects in animals, and its metabolite is detectable in plasma up to 2 years after discontinuation. Thus, in pregnant women, it is formally contraindicated; and pregnancy must be excluded before starting it. ${ }^{27}$

Methotrexate is another teratogenic drug, classified by the FDA as $\mathrm{X}$ (contraindicated in pregnancy). If used in the first trimester, it is associated to FGR and some major malformations, such as absence or hypoplasia of the frontal bones, craniosynostosis, large fontanelle and ocular hypertelorism. ${ }^{27}$

During the first trimester, rituximab has very low transplacental transfer, with some studies reporting safe pregnancies and deliveries in those cases of exposure. However, during the second or third trimester, it can cross the placenta and induce severe neonatal lymphopenia. ${ }^{27,37}$ Hence, in these cases, live vaccines should be avoided in those children during the first 6 months of life. ${ }^{27}$

Handling some complications that often affect pregnant women with SLE justifies a short statement. Since arterial hypertension is a common condition among patients with lupus nephritis, an appropriate management of blood pressure in pregnancy may reduce the progression of the disease and avoid several adverse pregnancy outcomes. Labetalol, nifedipine or methyldopa are safe drugs for treating hypertension. Angiotensin-converting-enzyme inhibitors should be avoided due to their association to multiple congenital abnormalities. $^{27}$

Low-dose aspirin is recommended, since it reduces the risk of preeclampsia and perinatal death; besides, it is associated with an increase in the birth weight of those with risk factors, including renal disease. Full anticoagulation with low-molecular weight heparin (LMWH) is recommended if there has been a previous thromboembolic event. ${ }^{27}$

Calcium supplementation is required, mainly for those women in use of corticosteroids and heparin. Supplemental vitamin $\mathrm{D}$ does not reduce the risks of unfavorable outcomes. $^{25}$

\section{Delivery Assistance}

Women with SLE have an increased risk of preterm delivery. This may occur spontaneously or because of maternal and/or fetal complications (such as severe lupus flare, preeclampsia and FGR). ${ }^{24}$

In gestational age between 24 weeks and 34 weeks and 6 days, accelerating of fetal lung maturation is essential, with two intramuscular steroid injections (preferably, betamethasone), independently of any maternal steroids administrated before. ${ }^{24}$

Magnesium sulfate should be considered when gestational age is $<32$ weeks, due to its neuroprotective benefits to the fetus. As it is well known, it ought to be administrated in cases of severe preeclampsia. ${ }^{24}$
The aim in a pregnant SLE patient should be to accomplish a spontaneous labor at term with vaginal delivery. However, available data have revealed that women with SLE are more expected to undergo a cesarean section ( $>33 \%$; odds ratio [OR] 1.7; confidence interval [CI] 95\% 1.6-1.9). In spite of that, it is recommended that $\mathrm{C}$-sections should be reserved only for obstetric indications, due to its extra risk factor for venous thromboembolism (VTE), blood loss and infection, as well as repercussions for future gestations. ${ }^{24}$

Adjusting maternal medication for labor may be required. Intravenous hydrocortisone may be necessary to overcome the physiological stress of labor if long-term oral steroids have been taken. If a woman receives standard prophylactic LMWH, it should be discontinued at the onset of spontaneous labor, as well as on the night before induced labor or elective cesarean section. Regional anesthesia (epidural or spinal) can be performed 12 hours after the last LMWH dose. ${ }^{24}$

\section{Postpartum Care}

Rigorous monitoring for severe maternal exacerbations is strongly recommended for those who had anticipated delivery because of a SLE flare or coexisting preeclampsia. The treatment for postpartum active SLE is similar to that for nonpregnant women. Nonetheless, it should be noticed that several medications for aggressive therapy are not recommended during breastfeeding. Thus, the risks and benefits of continuing breastfeeding must be clarified to the lactating mother. ${ }^{28}$

All women who received antenatal LMWH should continue its use for 6 weeks postpartum, in a prophylactic dosage, since puerperium is also a period of increased VTE risk. Afterward, the postpartum VTE risk should be assessed. ${ }^{24}$

In patients with SLE, postpartum counseling to offer safe contraception is particularly important. Good choices are long-acting reversible contraception (LARC) methods. They are considered reliable and less dependent on patient commitment. $^{24}$ Progestogen-only methods are safe and may become a suitable option. ${ }^{24}$

Estrogen-containing contraceptives must not be used by women with aPL antibodies or antiphospholipid syndrome (APS), moderate to severe active SLE (including lupus nephritis) and some other conditions, such as hypertension, smoking, obesity or previous VTE, since they increase a woman's VTE risk. In cases of well-defined SLE with stable and/or lowactive disease, the use of combined oral contraceptive may be suitable if wished. ${ }^{24}$ Barrier methods present a high failure rate (15-32\%); thus, they should not be used as single methods. ${ }^{24}$

\section{Discussion}

It is well established that pregnant women with SLE present a higher risk for maternal complications and pregnancy wastage, in spite of significant progress concerning success rates lately. During pregnancy, the disease activity may worsen and consequently rise the risk of other maternal and fetal complications. Therefore, holding an adequate control of disease activity and treating flares quickly must be a core-objective during prenatal care. 
Multidisciplinary care, coordinated by obstetricians and clinicians, with close monitoring, should allow for early diagnosis of complications.

Considering the data obtained on this review, the disease activity should be systematically evaluated by SLEPDAI, ${ }^{25,31,32,36}$ since it presents as the factor that guides adjustment or change in medication. All pregnant women with clinical suspicion of active or poorly controlled disease should be hospitalized due to the severity of the maternal condition and fast deterioration of fetal vitality conditions that may be associated with this event. ${ }^{24,25}$

Regarding the appropriate treatment, prednisone is an immunosuppressant that can be safely used during pregnancy. The association with gestational diabetes in lupus is low and is not a limiting factor for the use of medication. However, pregnant women using high doses should be screened for gestational diabetes. ${ }^{24}$ Hydroxychloroquine may be used during gestation, since it is associated with reduced disease activity. ${ }^{27,40,41}$

Azathioprine, tacrolimus and cyclosporine could be used as a therapeutic option in cases resistant to prednisone. Nonsteroidal anti-inflammatory drugs, leflunomide, cyclophosphamide, methotrexate and mycophenolate mofetil should not be prescribed. ${ }^{27,28,37,40,41}$

Furthermore, prophylaxis of preeclampsia should be performed with AAS $100 \mathrm{mg} / \mathrm{d}$ between 12 and 34 weeks of gestation and calcium carbonate $1.5 \mathrm{~g} / \mathrm{d}$ throughout the entire gestational period. ${ }^{24,40}$

We strongly recommend follow-up of fetal growth and vitality with serial sonography (at least one per trimester), Doppler velocimetry assessment from 26 weeks (repeated every 2 weeks if normal and weekly if altered), NST from 28 weeks and fetal echocardiography between 24 and 30 weeks for patients with anti-SSA. 29,39,42

Labor delivery must be determined according to obstetric indication and should occur no later than full-term. In the cases of patients taking corticosteroids at immunosuppressive dose $(1 \mathrm{mg} / \mathrm{kg}$ ), we recommend prophylactic antibiotics due to the risk of infections and sepsis. ${ }^{27,31}$

Contraceptive counseling may include LARC or progestogen-only methods and surgical sterilization (with social or medical indication). Combined oral contraceptives present relative contraindication, considering the risk of VTE. ${ }^{24,40}$

After all, it is important to notice that the present study had some limitations: randomized trials did not integrate this review, which would certainly increase its degree of evidence. However, it should be emphasized that SLE in pregnancy is a condition whose incidence is not so high, which could justify the lack of these trials. In addition, one cannot deny the existence of a publication bias, with often the best results disclosed to the scientific community.

On the other hand, there are strengths of this study that should be underlined: a wide variety of studies performed in different countries, with the opinions of several experts, each with varied backgrounds, were part of this integrative review. Besides, the lack of available meta-analysis reinforces the importance of including other reviews made by these specialists.

\section{Conclusion}

In conclusion, SLE pregnant women present an increased risk for maternal complications, pregnancy loss and other adverse perinatal outcomes. The diagnosis of the disease during pregnancy may be highly difficult, as well as the identification of worsening disease activity. These conditions, therefore, increase the risk of other maternal-fetal complications. Thus, close prenatal care, multidisciplinary team, adequate control of disease activity and treating flares quickly should be a central goal for better results

Conflicts of Interest

The authors have stated explicitly that there are no conflicts of interest in connection with this article.

\section{References}

1 Shaikh MF, Jordan N, D'Cruz DP. Systemic lupus erythematosus. Clin Med (Lond) 2017;17(01):78-83. Doi: 10.7861/clinmedicine.17-1-78

2 Sato EI. Lúpus eritematoso sistêmico. In: Borges DR, Rothschild HA, eds. Atualização Terapêutica: Manual Prático de Diagnóstico e Tratamento. 21 $1^{\mathrm{a}}$ ed. São Paulo, SP: Artes Médicas; 2003

3 Gómez-Puerta JA, Cervera R. Lupus eritematoso sistémico. Medicina \& Laboratorio 2008;14:221-223

4 Santamaria JR, Badziak D, Barros MF, Mandelli FL, Cavalin LC, Sato M. Síndrome antifosfolípide. An Bras Dermatol 2005;80:225-239. Doi: 10.1590/S0365-05962005000300002

5 American College of Rheumatology Ad Hoc Committee on Systemic Lupus Erythematosus Guidelines. Guidelines for referral and management of systemic lupus erythematosus in adults. Arthritis Rheum 1999;42(09):1785-1796. Doi: 10.1002/15290131(199909)42:9<1785:AID-ANR1 > 3.0.CO;2-\#

6 Borba EF, Latorre LC, Brenol JCT, et al. [Consensus of systemic lupus erythematosus]. Rev Bras Reumatol 2008;48:196-207. Doi: 10.1590/S0482-50042008000400002

7 Petri M, Orbai AM, Alarcón GS, et al. Derivation and validation of the Systemic Lupus International Collaborating Clinics classification criteria for systemic lupus erythematosus. Arthritis Rheum 2012;64(08):2677-2686. Doi: 10.1002/art.34473

8 Cortés-Hernández J, Ordi-Ros J, Paredes F, Casellas M, Castillo F, Vilardell-Tarres M. Clinical predictors of fetal and maternal outcome in systemic lupus erythematosus: a prospective study of 103 pregnancies. Rheumatology (Oxford) 2002;41(06):643-650. Doi: $10.1093 /$ rheumatology/41.6.643

9 Rahman FZ, Rahman J, Al-Suleiman SA, Rahman MS. Pregnancy outcome in lupus nephropathy. Arch Gynecol Obstet 2005;271 (03):222-226. Doi: 10.1007/s00404-003-0574-x

10 Warren JB, Silver RM. Autoimmune disease in pregnancy: systemic lupus erythematosus and antiphospholipid syndrome. Obstet Gynecol Clin North Am 2004;31(02):345-372, vi-vii

11 Zhan Z, Yang Y, Zhan Y, Chen D, Liang L, Yang X. Fetal outcomes and associated factors of adverse outcomes of pregnancy in southern Chinese women with systemic lupus erythematosus. PLoS One 2017;12(04):e0176457. Doi: 10.1371/journal.pone.0176457

12 Simard JF, Arkema EV, Nguyen C, et al. Early-onset preeclampsia in lupus pregnancy. Paediatr Perinat Epidemiol 2017;31(01):29-36. Doi: $10.1111 /$ ppe.12332

13 Chiu TF, Chuang YW, Lin CL, et al. Long-term outcomes of systemic lupus erythematous patients after pregnancy: a Nationwide Population-Based Cohort Study. PLoS One 2016;11(12):e0167946. Doi: 10.1371/journal.pone.0167946

14 Hussein Aly EA, Riyad RM, Mokbel AN. Pregnancy outcome in patients with systemic lupus erythematosus: a single center 
study in the High Risk Pregnancy unit. Middle East Fertil Soc J 2016;21:168-174. Doi: 10.1016/j.mefs.2015.12.003

15 Tedeschi SK, Guan H, Fine A, Costenbader KH, Bermas B. Organspecific systemic lupus erythematosus activity during pregnancy is associated with adverse pregnancy outcomes. Clin Rheumatol 2016;35(07):1725-1732. Doi: 10.1007/s10067-016-3270-5

16 Buyon JP, Kim MY, Guerra MM, et al. Predictors of pregnancy outcomes in patients with lupus: a Cohort Study. Ann Intern Med 2015;163(03):153-163. Doi: 10.7326/M14-2235

17 Chen S, Sun X, Wu B, Lian X. Pregnancy in women with systemic lupus erythematosus: a retrospective study of 83 pregnancies at a single centre. Int J Environ Res Public Health 2015;12(08): 9876-9888. Doi: 10.3390/ijerph120809876

18 Jakobsen IM, Helmig RB, Stengaard-Pedersen K. Maternal and foetal outcomes in pregnant systemic lupus erythematosus patients: an incident cohort from a stable referral population followed during 1990-2010. Scand J Rheumatol 2015;44(05): 377-384. Doi: 10.3109/03009742.2015.1013982

19 Tedeschi SK, Massarotti E, Guan H, Fine A, Bermas BL, Costenbader $\mathrm{KH}$. Specific systemic lupus erythematosus disease manifestations in the six months prior to conception are associated with similar disease manifestations during pregnancy. Lupus 2015;24 (12):1283-1292. Doi: 10.1177/0961203315586455

20 Madazli R, Yuksel MA, Oncul M, Imamoglu M, Yilmaz H. Obstetric outcomes and prognostic factors of lupus pregnancies. Arch Gynecol Obstet 2014;289(01):49-53. Doi: 10.1007/s00404-0132935-4

21 Fatemi A, Fard RM, Sayedbonakdar Z, Farajzadegan Z, Saber M. The role of lupus nephritis in development of adverse maternal and fetal outcomes during pregnancy. Int J Prev Med 2013;4(09): 1004-1010

22 Gaballa HA, El-Shahawy EED, Atta DS, Gerbash EF. Clinical and serological risk factors of systemic lupus erythematosus outcomes during pregnancy. Egyp Rheumatol. 2012;34:159-165. Doi: $10.1016 /$ j.ejr.2012.04.004

23 Surita FG, Parpinelli MA, Yonehara E, Krupa F, Cecatti JG. Systemic lupus erythematosus and pregnancy: clinical evolution, maternal and perinatal outcomes and placental findings. Sao Paulo Med J 2007;125(02):91-95. Doi: 10.1590/S1516-31802007000200005

24 Knight CL, Nelson-Piercy C. Management of systemic lupus erythematosus during pregnancy: challenges and solutions. Open Access Rheumatol 2017;9:37-53. Doi: 10.2147/OARRR.S87828

25 Lateef A, Petri M. Systemic lupus erythematosus and pregnancy. Rheum Dis Clin North Am 2017;43(02):215-226. Doi: 10.1016/j. rdc.2016.12.009

26 Østensen M. Preconception Counseling. Rheum Dis Clin North Am 2017;43(02):189-199. Doi: 10.1016/j.rdc.2016.12.003
27 Moroni G, Ponticelli C. Pregnancy in women with systemic lupus erythematosus (SLE). Eur J Intern Med 2016;32:7-12. Doi: 10.1016/ j.ejim.2016.04.005

28 Yamamoto Y, Aoki S. Systemic lupus erythematosus: strategies to improve pregnancy outcomes. Int J Womens Health 2016; 8:265-272. Doi: 10.2147/IJWH.S9015

29 de Jesus GR, Mendoza-Pinto C, de Jesus NR, et al. Understanding and managing pregnancy in patients with lupus. Autoimmune Dis 2015;2015:943490

30 Singh AG, Chowdhary VR. Pregnancy-related issues in women with systemic lupus erythematosus. Int J Rheum Dis 2015;18(02): 172-181. Doi: 10.1111/1756-185X.12524

31 Lateef A, Petri M. Managing lupus patients during pregnancy. Best Pract Res Clin Rheumatol 2013;27(03):435-447. Doi: 10.1016/j. berh.2013.07.005

32 Lateef A, Petri M. Management of pregnancy in systemic lupus erythematosus. Nat Rev Rheumatol 2012;8(12):710-718. Doi: 10.1038/nrrheum.2012.133

33 Stanhope TJ, White WM, Moder KG, Smyth A, Garovic VD. Obstetric nephrology: lupus and lupus nephritis in pregnancy. Clin J Am Soc Nephrol 2012;7(12):2089-2099. Doi: 10.2215/CJN.12441211

34 Baer AN, Witter FR, Petri M. Lupus and pregnancy. Obstet Gynecol Surv 2011;66(10):639-653. Doi: 10.1097/OGX.0b013e318239e1ee

35 Ruiz-Irastorza G, Khamashta MA. Lupus and pregnancy: integrating clues from the bench and bedside. Eur J Clin Invest 2011;41 (06):672-678. Doi: 10.1111/j.1365-2362.2010.02443.x

36 Buyon JP. Updates on lupus and pregnancy. Bull NYU Hosp Jt Dis 2009;67(03):271-275

37 Doria A, Tincani A, Lockshin M. Challenges of lupus pregnancies. Rheumatology (Oxford) 2008;47(Suppl 3):iii9-iii12. Doi: 10.1093/ rheumatology/ken151

38 Clowse ME. Lupus activity in pregnancy. Rheum Dis Clin North Am 2007;33(02):237-252, v

39 Witter FR. Management of the high-risk lupus pregnant patient. Rheum Dis Clin North Am 2007;33(02):253-265, v-vi

40 Andreoli L, Crisafulli F, Tincani A. Pregnancy and reproductive aspects of systemic lupus erythematosus. Curr Opin Rheumatol 2017;29(05):473-479. Doi: 10.1097/BOR.0000000000000415

41 Keeling SO, Oswald AE. Pregnancy and rheumatic disease: "by the book" or "by the doc". Clin Rheumatol 2009;28(01):1-9. Doi: 10.1007/s10067-008-1031-9

42 Andreoli L, Bertsias GK, Agmon-Levin N, et al. EULAR recommendations for women's health and the management of family planning, assisted reproduction, pregnancy and menopause in patients with systemic lupus erythematosus and/or antiphospholipid syndrome. Ann Rheum Dis 2017;76(03):476-485. Doi: 10.1136/annrheumdis2016-209770 